\title{
Role of Liver Transplantation in the Treatment of Hepatocellular Carcinoma
}

\author{
SHUNZABURO IWATSUKI, MD and THOMAS E. STARZL, MD, PhD \\ Department of Surgety, Transplant Institute, University of Pittsburgh School of Medidne, Pittsburgh, \\ Pennsylvania
}

\begin{abstract}
The results obtained by liver transplantation (TX) $(n=105)$ for hepatocellular carcinoma (HCC) were compared with those achieved by hepatic resection $(\mathrm{HX})(\mathrm{n}=76)$. Overall 1 - to 5-year survival rates after TX were 66\%, 49\%, 39\%, 36\%, and 36\%, and those after HX were 71\%, 55\%, 47\%, 37\%, and $33 \%$, respectively. The survival rates after TX and HX correlated well with pTNM stages, and the overall survival rates were similar in each stage between the TX and the HX group. However, when HCC was associated with cirrhosis of the liver, the survival rates after TX were significantly higher than those after HX at each stage of pTNM classification. Tumor recurrence rate was high both after TX (43\%) and HX (50\%), particularly in stage IV-A. Tumor recurrence rate was significantly lower after TX than after HX in HCCs of stages II and III. Liver TX has established its definite role in the treatment of $\mathrm{HCC}$, particularly in the presence of hepatic impairment or cirrhosis of the liver.
\end{abstract}

\section{Keywords}

hepatic resection; liver cirrhosis; survival rates

\section{INTRODUCTION}

In the early trials of liver transplantation (TX), total hepatectomy and liver replacement (orthotopic liver TX) were thought to be an ideal therapy for primary hepatic malignancy that could not be removed by conventional techniques of subtotal hepatic resection (HX). The enthusiasm for this approach was soon dampened by the high recurrence rate of original malignancies after successful transplantation [1-4], and the role of liver TX in cancer therapy has been seriously questioned. Nevertheless, the efforts to treat malignant tumors by liver TX have been continued because of: 1) the lack of other effective therapy; 2) occasional long-term survival and excellent palliation; and 3) the much improved overall survival after liver TX with cyclosporine-steroid therapy during the last decade.

Recently we have reviewed our experiences in the treatment of hepatocellular carcinoma (HCC) either by orthotopic liver TX or by conventional subtotal hepatectomy during the era of cyclosporine (1980-1989) [5]. The comparisons between the results obtained by liver TX and those by HX led us to understand the pros and the cons of either therapy in the various stages of HCC. 


\section{PATIENTS AND METHODS}

During the 10-year period between 1980 and 1989, 105 patients with HCC were treated by orthotopic liver TX under cyclosporine-steroid immunosuppressive therapy and an additional 76 patients by subtotal HX at the University of Colorado Health Sciences Center (1980) and the University Health Center of Pittsburgh (1981-1989).

Subtotal HX was considered as the first treatment of choice for HCC when it was anatomically and functionally feasible. Liver TX was used if HX was not feasible due to extensive hepatic involvement of malignancy or if the underlying liver disease and/or hepatic failure precluded this possibility. One third of the patients in the transplant group had extensive HCC in the normal liver which could only be removed by total hepatectomy, one third had HCC in advanced cirrhosis of the liver, and one third had misdiagnosed HCC in the failing liver for which liver TX was performed.

\section{RESULTS AND DISCUSSION}

Overall survivals of the 105 patients who received liver TX in the presence of HCC and those of the 76 patients who underwent HX for HCC were similar as shown in Figure 1. As the indication for TX differs from that of HX, the comparison between these two therapeutic modalities in overall survival rates has little value. Therefore, the stages of HCC in the TX group and the HX group were stratified according to the pTNM classification (Table I) [6,7] and are shown in Table II.

There were only four patients with stage I HCC. all of whom received liver TX. One of the four patients died of transplant-related complications, but the other three patients were alive, free of tumor 2-5 years after TX (1-5-year survival rates of 75\%).

The survival rates after TX and after HX were compared in pTNM stages II through IV-A, and shown in Figure 2. The pTNM stage correlated well with the survival rates both in the TX and the HX groups. In both groups the survival rates of stage IV-A patients were significantly ( $P$ $<0.05)$ lower than those of other stages. There was no statistically significant difference in the survival rates when they were compared in the same pTNM stages between the TX group and the HX group (Fig. 2).

Because the presence of associated cirrhosis of the liver with $\mathrm{HCC}$ or hepatic dysfunction was a major factor in choosing either TX or HX therapy, the survival rates were compared between the patients with associated cirrhosis and those without it both in the TX group and the HX group (Fig. 3). When HCC was associated with cirrhosis of the liver, the survival rates were significantly $(P=0.001)$ lower than those with-out cirrhosis in the HX group, but the survival rates were similar in the TX group. The survival rates of the TX group were significantly $(P$ $=0.002$ ) higher than those of the HX group when HCC was associated with cirrhosis of the liver, but they were similar when HCC was not associated with cirrhosis. There were no 4-year survivors after HX among the patients with HCC in the cirrhotic liver, but the 5-year survival rate after TX was $41 \%$.

The survival rates of patients with HCC in the cirrhotic liver were compared between the TX group and the HX group in the same pTNM stages and are shown in Figure 4. The survival rates of the TX group were higher than those of the HX group in stages II through IV -A, and the difference was most striking in stage III.

The recurrence of $\mathrm{HCC}$ was confirmed in 45 (43\%) of the 105 patients in the TX group and in $38(50 \%)$ of the 76 patients in the HX group during the following period (18-132 months). Although overall incidence of tumor recurrence was similar for the TX group and the HX 
group, the HCCs of stages II and III recurred significantly $(P=0.003)$ more frequently in the HX group than in the TX group (Table III). The incidence of tumor recurrence in stage IV-A was extremely high: $68 \%$ in the TX group and $60 \%$ in the HX group.

Sixty-seven (64\%) of the 105 patients in the TX group and 48 (63\%) of the 76 patients in the HX group died during the follow-up period (Table III). Approximately two thirds of deaths were directly and in-directly related to the tumor recurrence, both in the TX group and the HX group. Approximately one fifth of the patients in the TX group and in the HX group died of various causes that were not related to tumor recurrence. It is worth noting that tumor-related death among the patients with stage II and III HCC was statistically $(P=0.013)$ more frequent in the HX group than in the TX group (Table III). Tumor-related death was quite frequent among patients in stage IV-A tumor both in the TX group and the HX group (Table III).

From the results presented above, the role of liver TX in the treatment of HCC has become somewhat clearer than it used to be. Liver TX and HX are equally effective treatments for HCC in terms of overall survival rates (Fig. 1). In treating the HCCs developed in the cirrhotic liver, however, liver TX can provide higher survival rates in each stage of the pTNM classification than HX (Fig. 4). Tumor recurrence rate and deaths from recurrent $\mathrm{HCC}$ are significantly higher after HX than after liver TX for HCCs in stages II and III (Table III).

\section{CONCLUSION}

It is reasonable to conclude from our experience that liver TX has its definite role in the treatment of HCC, particularly when stage II and III HCCs are associated with cirrhosis of the liver. High recurrence rates of stage IV-A HCC both after transplant and resection are discouraging. The accelerated growth rate of HCC under immunosuppressive therapy has been documented [8]. Systematic neoadjuvant and adjuvant chemotherapy have been under investigation at our institute for the last 2 years. The preliminary results appear to be rather encouraging, but a longer follow-up is needed to determine the effectiveness of adjuvant chemotherapy.

\section{REFERENCES}

1. Starzl, TE. Experience in Hepatic Transplantation. WB Saunders; Philadelphia: 1969. p. 284-298.(with the assistance CW Putnam)

2. Caine, RY. Liver transplantation. In: Caine, RY., editor. The Cambridge and King's College Hospital Experience. Grune and Stratton; London: 1893. p. 306-311.

3. O'Grady JA, Polson RJ, Rolles K, et al. Liver transplantation for malignant disease. Results in 93 consecutive patients. Ann Surg 1988;207:373-379. [PubMed: 2451484]

4. Ringe B, Wittekind C, Bechstein WO, et al. The role of liver transplantation in hepatobiliary malignancy. Ann Surg 1989;290:88-98. [PubMed: 2535924]

5. Iwatsuki S, Starzl TE, Sheahan DG, et al. Hepatic resection versus transplantation for hepatocellular carcinoma. Ann Surg 1991;214:221-229. [PubMed: 1656903]

6. Hermanek, P.; Sobin, LH., editors. TNM Classification of Malignant Tumours. Fourth, Fully Revised Edition. Springer-Verlag; Berlin: 1987. p. 53-55.

7. American Joint Committee on Cancer. Manual for Staging of Cancer. 3rd Edition. JB Lippincott; Philadelphia: 1987. p. 87-92.

8. Yokoyama I, Carr B, Saitsu H, et al. Accelerated growth rates of recurrent hepatocellular carcinoma after liver transplantation. Cancer 1991;68:2095-2100. [PubMed: 1655200] 


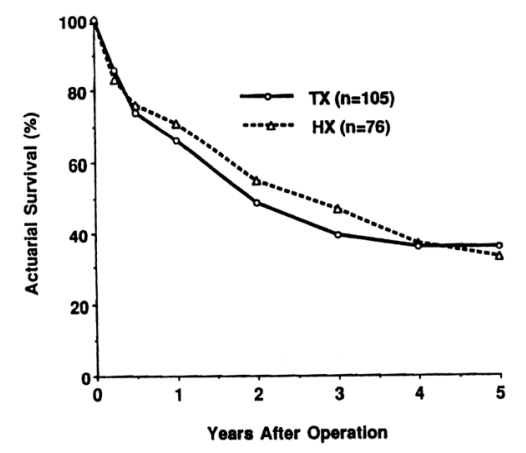

Fig. 1.

Overall survival rates after liver TX and HX for HCC. 


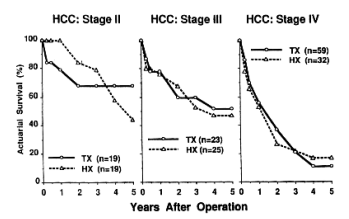

Fig. 2.

Survival rates after liver TX and after HX for stages II to IV-A HCC. 


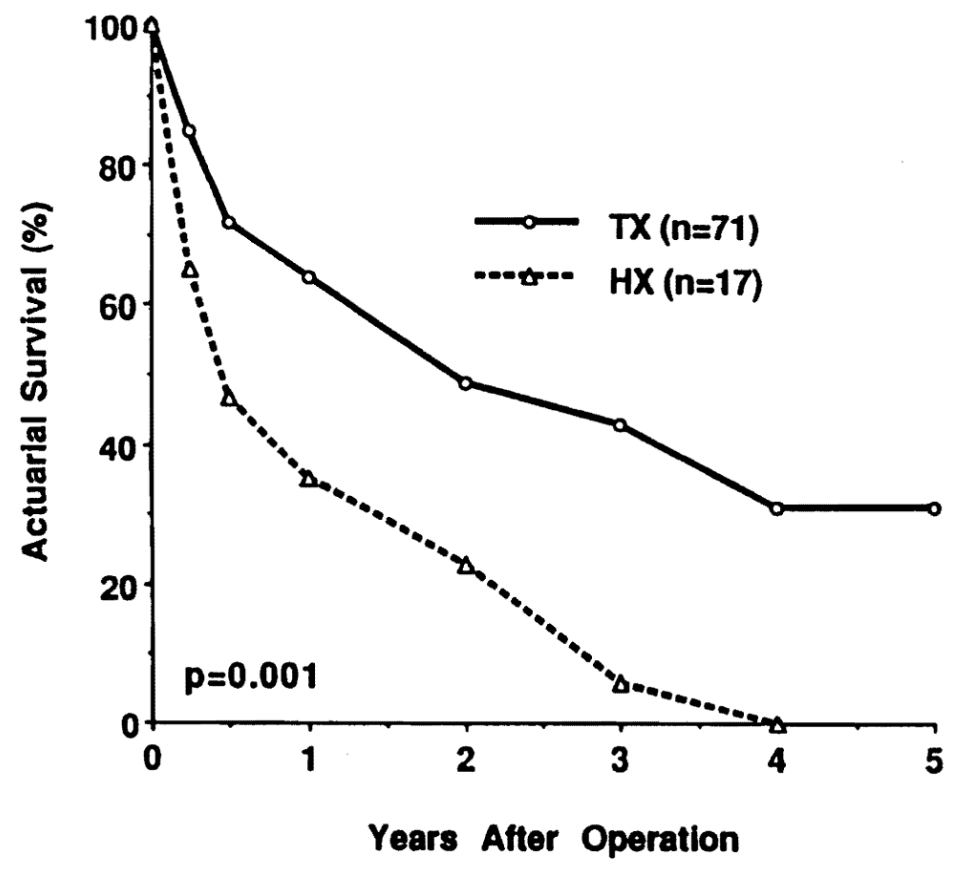

Fig. 3.

Survival rates after liver TX and after HX for $\mathrm{HCC}$ in cirrhosis of the liver. 


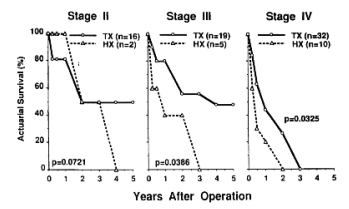

Fig. 4.

Survival rates after liver TX and after HX for stages II to IV-A HCC in cirrhosis of the liver. 


\section{TABLE I}

pTNM Pathologic Classification of HCC

\begin{tabular}{llll}
\hline Stage I & T1 & N0 & M0 \\
Stage II & T2 & N0 & M0 \\
Stage III & T1 & N1 & M0 \\
& T2 & N1 & M0 \\
& T3 & NO,N1 & M0 \\
Stage IVA & T4 & Any N & M0 \\
Stage IVB & Any T & Any N & M1 \\
\hline
\end{tabular}

* T1, Solitary, $\leq 2 \mathrm{~cm}$, without vascular invasion; $\mathrm{T} 2$, solitary, $\leq 2 \mathrm{~cm}$, with vascular invasion. Multiple, one lobe, $\leq 2 \mathrm{~cm}$, without vascular invasion; T3, solitary, $>2 \mathrm{~cm}$, with vascular invasion. Multiple, one lobe, $>2 \mathrm{~cm}$, with or without vascular invasion; T4, multiple, more than one lobe. Invasion of major branch of portal or hepatic veins; N1, regional lymph node; M1, distant metastasis. 


\section{TABLE II}

pTNM Stages of 105 Patients in TX Group and 5 Those of 76 Patients in HX Group

\begin{tabular}{lrr}
\hline pTNM stage & TX group & HX group \\
\hline I & 4 & 0 \\
II & 19 & 19 \\
III & 23 & 25 \\
IV-A & 59 & 32 \\
Total & 105 & 76 \\
\hline
\end{tabular}




\section{TABLE III}

Tumor Recurrence and Causes of Death of HCC: TX vs. HX

\begin{tabular}{|c|c|c|c|}
\hline & $\begin{array}{l}\text { Recurrence } \\
\text { of tumor } \\
(\%)\end{array}$ & $\begin{array}{l}\text { Death with } \\
\text { tumor } \\
(\%)\end{array}$ & $\begin{array}{r}\begin{array}{r}\text { Death without } \\
\text { tumor } \\
(\%)\end{array}\end{array}$ \\
\hline \multicolumn{4}{|l|}{ TX group } \\
\hline Stage I $(n=4)$ & $0(0)$ & $0(0)$ & $1(25.0)$ \\
\hline Stage II $(n=19)$ & $1(5.3)$ & $1(5.3)$ & $6(31.6)$ \\
\hline Stage III $(\mathrm{n}=23)$ & $4(17.4)$ & $3(13.0)$ & $8(24.8)$ \\
\hline $\begin{array}{l}\text { Stage IV-A } \\
(\mathrm{n}=59)\end{array}$ & $40(67.8)$ & $38(64.4)$ & $10(16.9)$ \\
\hline Total $(\mathrm{n}=105)$ & $45(42.9)$ & $42(40)$ & $25(23.8)$ \\
\hline \multicolumn{4}{|l|}{ HX group } \\
\hline Stage II $(\mathrm{n}=19)$ & $10(52.6)$ & $8(42.1)$ & $2(10.5)$ \\
\hline Stage III $(\mathrm{n}=25)$ & $9(36.0)$ & $7(28.0)$ & $6(24.0)$ \\
\hline $\begin{array}{l}\text { Stage IV-A } \\
\quad(\mathrm{n}=32)\end{array}$ & $19(59.4)$ & $17(53.1)$ & $7(21.9)$ \\
\hline Total $(\mathrm{n}=76)$ & $38(50.0)$ & $32(42.1)$ & $15(19.7)$ \\
\hline
\end{tabular}

